\title{
Muddling thru models
}

$\mathrm{N}$ o one doubts that the task developing models for global monitoring of noncommunicable diseases and the social determinants of health - will be tricky.

But when surveillance mandarins from 15 nations gathered in Toronto, Ontario in the wake of a pair of highlevel United Nations conferences that tasked the community with developing new surveillance models, it quickly became apparent that the task may well be more challenging than anyone imagined.

Squabbles erupted over the criteria, the methodology and even the value of multifactorial models of measurement. And while the delegates to the World Alliance for Risk Factor Surveillance (WARFS) Global Conference applauded the UN calls for monitoring the social and economic factors that underlie health conditions, they also indicated that surveillance practices need urgent updating to achieve such objectives.

The recently adopted UN Political Declaration on Non-communicable Diseases compels the World Health Organization to establish a global surveillance noncommunicable diseases network (www.cmaj.ca/lookup/doi/10.1503/cmaj .109-4011), while the nonbinding Rio Declaration on Social Determinants of Health, which emerged from a UN conference in Brazil, called on governments to, among other things "establish, strengthen and maintain monitoring systems that provide disaggregated data to assess inequities in health outcomes" (www.cmaj.ca/lookup/doi/10.1503/cmaj .109-4035).

But fierce debate flared among the surveillance mandarins about whether such factors as income levels, education, residential status, employment conditions, urbanization and community development ought to be tracked within health surveys, which traditionally deal with biological and behavioural factors such as family history, physical exercise, and tobacco and alcohol usage.

"Countries have to move from single

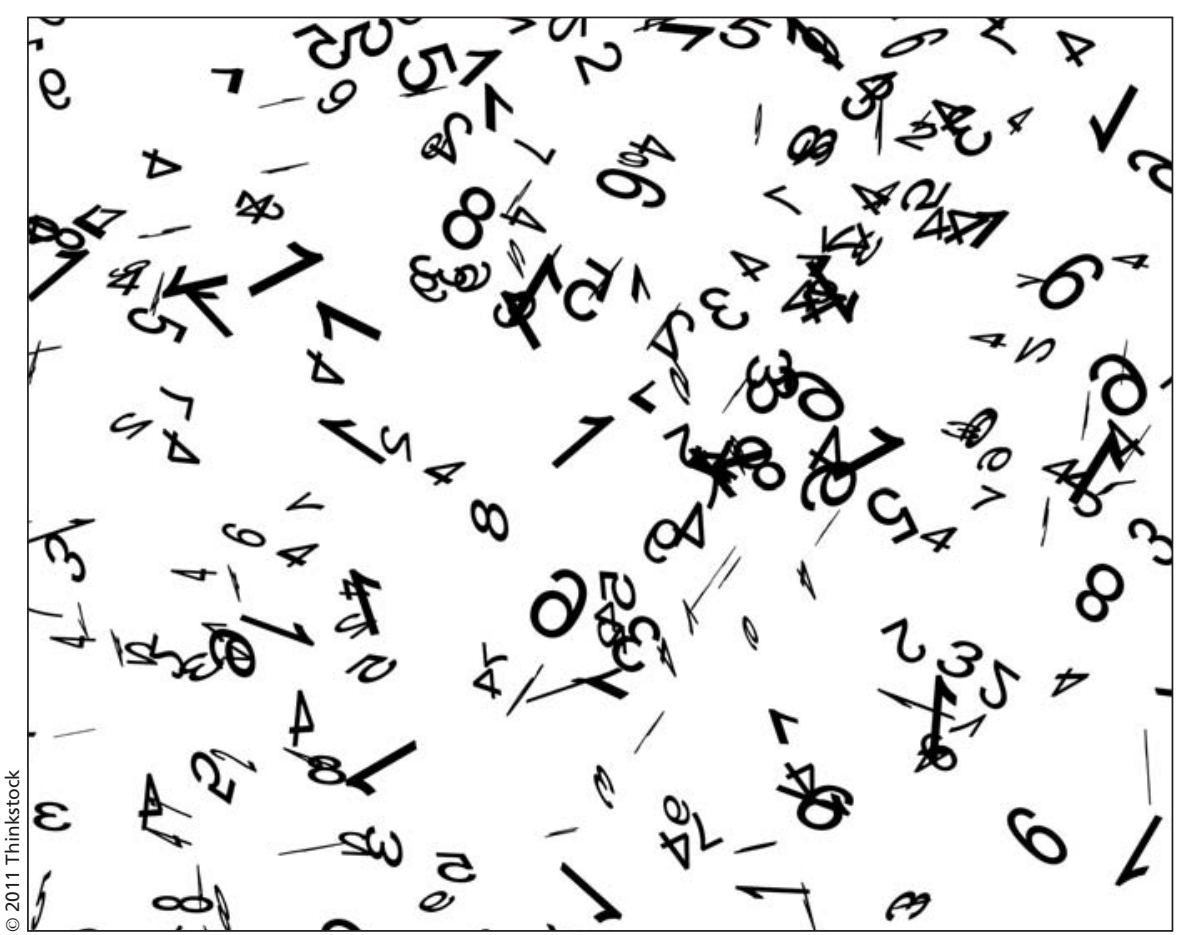

Experts argue that current World Health Organization surveillance methodologies will require fundamental reforms so as to properly acquire and organize data about noncommunicable diseases and the social determinants of health.

issue surveillance of factors like tobacco use to multi-issue and continuous surveillance," argued Dr. Isabella Danel, associate director for program development at the United States Centers for Disease Control and Prevention's (CDC) Center for Global Health.

Expanding surveillance to include social inequities will inevitably add a contentious political dimension to discussions of why some groups are healthier than others, said David McQueen, a consultant and former associate director for global health promotion at the CDC's National Center for Chronic Disease Prevention and Health Promotion. "The worry is that for political reasons we are not asking the right questions. No health surveillance system has effectively addressed the causes of the causes of health problems."

Expanding surveillance to include social factors could allow far earlier identification of emerging health issues, such as the changing behaviours that caused obesity to escalate in Western nations, said Thomas Abel, professor of health research at the Institute of Social and Preventive Medicine at the University of Bern in Switzerland. "We need monitoring systems that allow us to track changes in the conditions required by people to live a healthy life. Unfortunately, however, we face reluctance to do this. As a result, the truly important questions that should be included in surveys and questionnaires are not there yet."

Although several delegates argued that social determinants, rather than lifestyle factors, account for as much as $80 \%$ variations in health conditions amongst individuals, there was little concurrence on what additional indicators should be included in expanded health surveillance programs.

Bernard Choi, senior research scientist at the Public Health Agency of Canada, argued social determinants including income levels should be distinguished 
from risk factors such as alcohol and tobacco consumption, and that surveillance should concentrate on the latter.

Stefano Campostrini, professor of social statistics at the University of Ca' Foscari of Venice, Italy, argued that, at the very least, surveillance must be expanded to include income and education, while Dennis Raphael, professor of Health Policy and Management at York University in Toronto, favoured the inclusion of an even broader array of factors such as early life conditions, social exclusion, abo- riginal and ethnic status, employment benefits and unionization. Dr. Juan Zevallos, director of the Endowed Health Services Research Center of the University of Puerto Rico School of Medicine, noted that residents of poor countries are typically exposed to more health risk factors.

The plurality of views may well muddle the debate and undermine efforts to develop a multifactorial surveillance model, warned Dr. Harry Rutter, director of the National Obesity Observatory in Oxford, England.
"Unless we are clear on what the outcomes are that we are tracking, we are going to fumble this."

Danel cautioned that surveillance change will not come readily as government are unaccustomed to taking "a more holistic" approach to understanding health risks. "The social determinants are very complex. It's going to take a long time to figure this out. And surveillance can only go so far." - Paul Christopher Webster, Toronto, Ont.

CMAJ 2011. DOI:10.1503/cmaj.109-4042 